\title{
Aprendendo sobre o uso da Robótica para Introdução à Programação: um relato de experiência
}

\author{
Enza Rafaela De Nadai Victal ${ }^{1}$, Alex Premoli Cândido²
}

\begin{abstract}
1Departamento de Informática - Faculdade Pitágoras Guarapari Rodovia Jones dos Santos Neves - 29.214-005 - Guarapari - ES - Brasil

2Programa de Graduação - Universidade Federal do Espírito Santo (UFES)

Alto Universitário, S/N, Guararema - 29.500-000 - Alegre - ES - Brasil

\{enza.victal@kroton.com.br, alexpcandidoo@gmail.com\}
\end{abstract}

\begin{abstract}
Educational Robotics has been inserting itself as an interesting technological practice to be inserted in the classroom, as a learning support tool. There are numerous positive arguments that justify this practice and are reported in this article, besides the experimentation of robotics as a precursor of the narrated programming, through practical educational activities of beginning students of the Computer Science college, who created real projects, and mostly affordable, using Arduino. The aim is to show how robotics can contribute to a constructivist practice, which is beyond the traditionalism that involves instructional teaching, with an action research methodology.
\end{abstract}

Resumo. A Robótica Educacional vem se inserindo como uma prática tecnológica interessante de ser inserida em sala de aula, como ferramenta de apoio à aprendizagem. São inúmeros os argumentos positivos que justificam essa prática e que são relatados neste artigo, além da experimentação da robótica como precursora da programação que é narrada, através de atividades educacionais práticas de alunos iniciantes do curso superior de Ciência da Computação, que criaram projetos reais, e, principalmente, acessíveis, com uso de Arduino. O objetivo deste artigo é mostrar como a robótica pode contribuir para uma prática construtivista, que foge do tradicionalismo que envolve o ensino instrucional, por meio de uma metodologia de pesquisa-ação.

\section{Introdução}

No século XXI é sustentável afirmar que a Robótica Educacional está presente em instituições de ensino, centros educacionais e laboratórios de pesquisa. Metodicamente utilizada como instrumento que possibilita a criação de uma aula prática e comunicativa, desenvolvendo um ambiente interativo entre aluno e professor, despertando o interesse e atração através da ciência tecnológica, possibilitando a edificação do conhecimento em uma ambiência pedagógica que, a princípio, não existia [Zanetti e Bonacin 2014].

Benitti et al. [2009] definem a Robótica Educacional sendo uma disciplina propulsora de interesse, que pode ser utilizada para motivar os alunos em disciplinas consideradas de árduo entendimento, como, por exemplo, as de programação, devido ao alto índice de abstração exigido na disciplina. 
Neste trabalho é relatada uma experiência com a utilização do microcontrolador Arduino, motores, sensores e seu IDE (Ambiente de Desenvolvimento Integrado) de programação, para o ensino de robótica como precursora de programação para iniciantes do ensino superior de Ciência da Computação da Faculdade Pitágoras, campus Guarapari.

A plataforma Arduino é um exemplo de hardware livre, de baixo custo e fácil manuseio e possibilita a criação de uma diversidade de projetos. $\mathrm{O}$ seu uso torna-se interessante por trazer consigo não apenas o uso da programação, mas também a questão da multidisciplinaridade que é frequente na robótica: a manipulação do microcontrolador incute a aprendizagem de circuitos elétricos, conceito e funcionamento de portas digitais e analógicas e de eletrônica em geral.

E esta escolha de uso da robótica é justificada pela motivação de que uma aula prática, unificada às aulas teóricas, se torna essencial para o desenvolvimento $\mathrm{e}$ aprendizado dos alunos, aplicando a teoria e o conteúdo de forma prática utilizando o conhecimento em equipamentos reais com intuito de obter resultados autênticos.

As próximas seções estão apresentadas da seguinte forma: na Seção 2 fala-se sobre o porquê da robótica ser uma aliada ao ensino, com alguns pontos defensivos de sua aplicação na educação. Na Seção 3 está descrita a Metodologia da Pesquisa utilizada, juntamente com um detalhamento de materiais. A Seção 4 detalha todo percurso de criação e desenvolvimento dos projetos relatando as experiências e aprendizagens. E por fim, a Seção 5 mostra a importância do professor como mediador nesse contexto de utilização de robótica, seguido das Conclusões.

\title{
2. O porquê da Robótica Aplicada à Educação
}

Em vez de usar lousa, quadro, giz e pincel, a sala de aula é composta e abre espaço para componentes eletrônicos, ligações elétricas, furadeiras e parafusos. Como tema central e espinha dorsal da aula, o professor propõe a criação de um arquétipo robótico, com o intuito de despertar nos alunos a curiosidade somada à aprendizagem, dando ao aluno a possibilidade de ser parte central dessa metodologia educacional.

Esta aula é denominada Robótica Educacional.

\begin{abstract}
A Robótica Educacional provém [...] de uma necessidade que passou a existir com o avanço e a disseminação da tecnologia, devendo estar, portanto, atrelada ao desenvolvimento tecnológico com o passar dos anos. Ou seja, a Robótica Educacional tem seu início quando pesquisadores vislumbraram a possibilidade de inserção da tecnologia no processo ensino-aprendizagem; e deve evoluir em suas metodologias conforme a tecnologia e suas influências na sociedade forem evoluindo. [Bortolazza et al. 2014, p. 02]
\end{abstract}

A Robótica Educacional partiu então da necessidade de trazer para a escola tradicional o que é novo, mas não apenas por este motivo, mas também porque, com base nos estudos de Campos (2012), na tecnologia educacional, que utiliza não apenas a robótica mas também outras tecnologias, possui um enfoque construtivista, pois permitem que os alunos selecionem e desenvolvam suas próprias estratégias e são encorajados a buscar novos domínios do conhecimento.

É sabido da importância da educação, pois ela forma o indivíduo moderno e tem papel na preparação para a vida em sociedade, com todos os seus desafios reais. Por este fato, a Robótica Educacional traz um diferencial, pois torna o aprendizado não apenas 
dinâmico, mas também atraente e divertido para os alunos, tanto pela ludicidade como pela oportunidade de formar conhecimentos [Bortolazza et al., 2014].

A programação, por sua vez, é considerada a base para o curso de Ciência da Computação, e também faz parte do plano curricular de outros cursos por possuir característica interdisciplinar, estabelecendo relações com outras disciplinas, como os cursos de Engenharia, por exemplo. Esta disciplina aborda princípios de programação lógica desenvolvendo a capacidade de raciocínio lógico dos alunos e, através de análises, permitem que estes resolvam problemas por meio de algoritmos. A disciplina de programação, que tem altos índices de evasão e reprovação, é uma das dificuldades existentes nos cursos de graduação na área de computação e engenharias, tendo seu maior índice no curso de computação, dificultando e sendo um motivo desistência, impedido a continuidade dos alunos no curso [Rapkiewicz et al. 2006].

Os modelos pedagógicos, muitas vezes instrucionistas - fundado em aula, prova e repasse, também são fatores que podem dificultar a aprendizagem do aluno, que acaba perdendo o interesse necessário em disciplinas importantes. Este modelo tem como principal intuito fazer com que o professor não seja pautado somente como um transmissor de conhecimento, mas que seja uma ponte entre conhecimento e o aluno, adotando uma abordagem mais construtivista [Moretto 2000].

Diante de tantos obstáculos, a Robótica Educacional, com suas características interativas, acaba se tornando ferramenta essencial para a aprendizagem do aluno, dando ao estudante a possibilidade de explorar novas ideias. Sendo assim, do Rocio Zilli [2004] enfatiza que a disciplina fomenta algumas capacidades, como:

- Raciocínio lógico;

- Habilidades manuais e estéticas;

- Relações interpessoais e intrapessoais;

- Utilização de conceitos adquiridos em diferentes áreas do conhecimento para o desenvolvimento de projetos;

- Investigação e compreensão;

- Representação e comunicação;

- Trabalho com pesquisa;

- Resolução de problemas por meio de erros e acertos;

- Aplicação das teorias formuladas a atividades concretas;

- Utilização da criatividade em diferentes situações;

- Capacidade crítica, dando um leque vasto de possibilidades de dinâmica de aula, desenvolvendo métodos pedagógicos que facilitam o entendimento de matérias consideradas de maior dificuldade.

Métodos pedagógicos esses que potencializam o entendimento despertando o interesse do aluno. Nesse contexto, fica entendido que o processo de construtivismo relacionado ao uso da Robótica Educacional é caracterizado por um dinamismo do ensino em virtude do aluno não ser um objeto passivo. Isso porque, do início ao fim, a partir da confecção do robô até a programação, o aluno passa por muitas etapas onde a interação deixa esse processo mais prazeroso e produtivo. Justamente porque a prática do ensino em teoria foi colocada em ação, facilitando a assimilação do conhecimento pelos discentes [Lopes et al., 2018]. 
VIII Congresso Brasileiro de Informática na Educação (CBIE 2019)

Anais do XXV Workshop de Informática na Escola (WIE 2019)

\section{Metodologia e Materiais}

Esta seção apresenta os procedimentos, métodos e materiais adotados para execução deste relato de experiência envolvendo alunos iniciantes no ensino superior de Computação. A turma compunha-se de 15 alunos iniciantes, muitos dos quais nunca tiveram contato com programação.

Unindo-se a eles, mais 15 alunos veteranos (do terceiro período), com um pouco mais de experiência em programação, possibilitaram criar aulas guiadas, com uma metodologia do tipo pesquisa-ação. Thiollent [1985] define a pesquisa-ação como "um tipo de pesquisa que é concebida e realizada em estreita associação com uma ação ou ainda, com a resolução de um problema coletivo, onde todos os pesquisadores e participantes estão envolvidos de modo cooperativo e participativo".

Desta forma, os alunos trabalharam colocando em prática o conceito de aprender a aprender (que está ligado à linha construtivista que teve como um de seus iniciantes Jean Piaget) e o apender a ensinar. A Teoria Construtivista é uma das teorias mais importantes na educação, criada no século $\mathrm{XX}$, a partir das experiências de Piaget observando crianças desde o nascimento até a adolescência e percebeu que $o$ conhecimento se constrói na interação do sujeito com o meio em que ele vive [Piaget, 1970].

As atividades foram realizadas semanalmente em estruturas oferecidas pela instituição de ensino, em aulas laboratoriais, o que permitiu aulas mais dinâmicas e descontraídas, com trocas de experiências e auxílio para resolução de problemas em grupo.

Para as aulas, foram utilizadas tanto a prática com hardware quanto com software. No que diz respeito ao hardware, utilizou-se o Arduino Uno (Figura 1, à esquerda) que é um microcontrolador ATMega328, um sistema embarcado que possui memórias, processador, pinos de entrada ou saída, tudo encapsulado dentro de uma placa, capaz de armazenar e executar programas. Também foram utilizados diversos componentes que podem ser implementados no Arduino (Figura 1, à direita) como: leds, jumpers, protoboard, botões e, imprescindivelmente, os sensores.

O Arduino Uno é usado preferencialmente como primeira opção dos usuários, pois apresenta um custo baixo se comparado às demais placas e uma suficiente quantidade de portas e tamanho de memória.

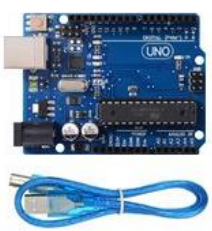

a.

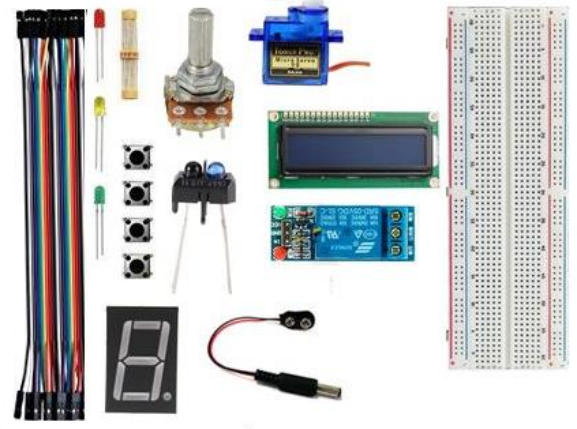

b.

Figura 1 - À esquerda o Arduino Uno (a) e à direita seus componentes (b)

Os sensores foram componentes essenciais, pois é o que materializa os estímulos que um projeto robótico pode receber ou emitir, como a exemplo do sensor ultrassônico, 
VIII Congresso Brasileiro de Informática na Educação (CBIE 2019)

Anais do XXV Workshop de Informática na Escola (WIE 2019)

que foi utilizado em um dos trabalhos (detalhado na seção subsequente). Este sensor é capaz de detectar obstáculos e fornecer à qual distância eles se encontram.

Com relação ao software, utilizou-se o próprio IDE do Arduino, um editor de código que é capaz de compilar e carregar programas para a placa com um único clique, ou seja, nada mais é que o ambiente onde se programa o que o Arduino irá fazer. O Arduino IDE, apresentado na Figura 2, abaixo, é gratuito e multiplataforma, o que o deixa mais acessível por ser uma ferramenta de baixo custo.

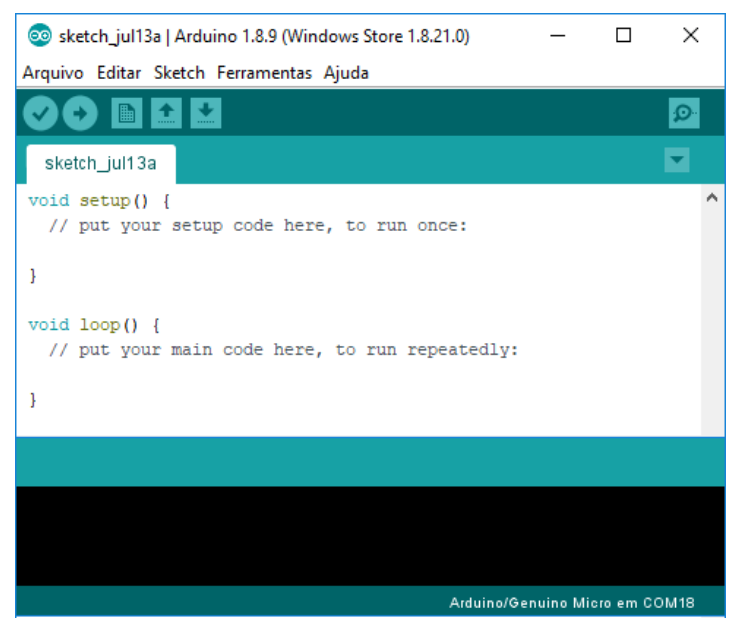

Figura 2 - Arduino IDE.

Importante ressaltar que este IDE foi esquematizado para introduzir a programação para pessoas não familiarizadas com o desenvolvimento de software, o que significa que já foi projetado para ser de fácil manipulação, o que possibilita a introdução à programação sem apresentar possíveis dificuldades.

\section{Experiências e Aprendizagens na Prática: a evolução dos projetos}

A primeira etapa foi marcada pela familiarização dos alunos iniciantes com os recursos de hardware e software. Nesta etapa, os alunos veteranos realizaram uma explanação do conteúdo por meio de uma aula introdutória, com um roteiro pré-elaborado. $\mathrm{Na}$ oportunidade, os alunos com mais construção de saberes (veteranos) sobre o tema citado, apresentaram o Arduino aos iniciantes e os auxiliaram com exemplos mais básicos, como acender e piscar leds e criação de semáforos.

Essa abordagem contribuiu no processo como um todo, primeiramente devido ao enfoque na prática construtivista, onde os alunos veteranos deixaram de ser apenas expectadores e assumiram a posição de ensinar. E isso tem seu valor, onde Freire (1997) já afirmava que "quem ensina aprende ao ensinar e quem aprende ensina ao aprender".

A segunda etapa foi a definição de grupos, que se reuniram e levantaram ideias de projetos. Após definirem seus projetos, cada grupo apresentou a sua escolha e em seguida se reuniram para inventariação de materiais a serem utilizados.

Desde o início, foi ressaltado aos alunos da importância e papel da robótica para o aprendizado da programação, aliando isto ao fato de que iriam ver na prática o resultado dos programas desenvolvidos por eles.

Todos os alunos realizaram trocas extraclasse, através de grupos criados em rede social de mensagem instantânea, o que facilitou o processo de troca de informações, 
VIII Congresso Brasileiro de Informática na Educação (CBIE 2019)

Anais do XXV Workshop de Informática na Escola (WIE 2019)

distribuição e delegação de tarefas, marcação de reuniões, informativos de problemas e soluções.

Posteriormente, as aulas práticas foram iniciadas (Figura 3), com a manipulação dos materiais complementares para montagem da estrutura: como madeira MDF, parafusos, solda, papelão e madeira reciclada.
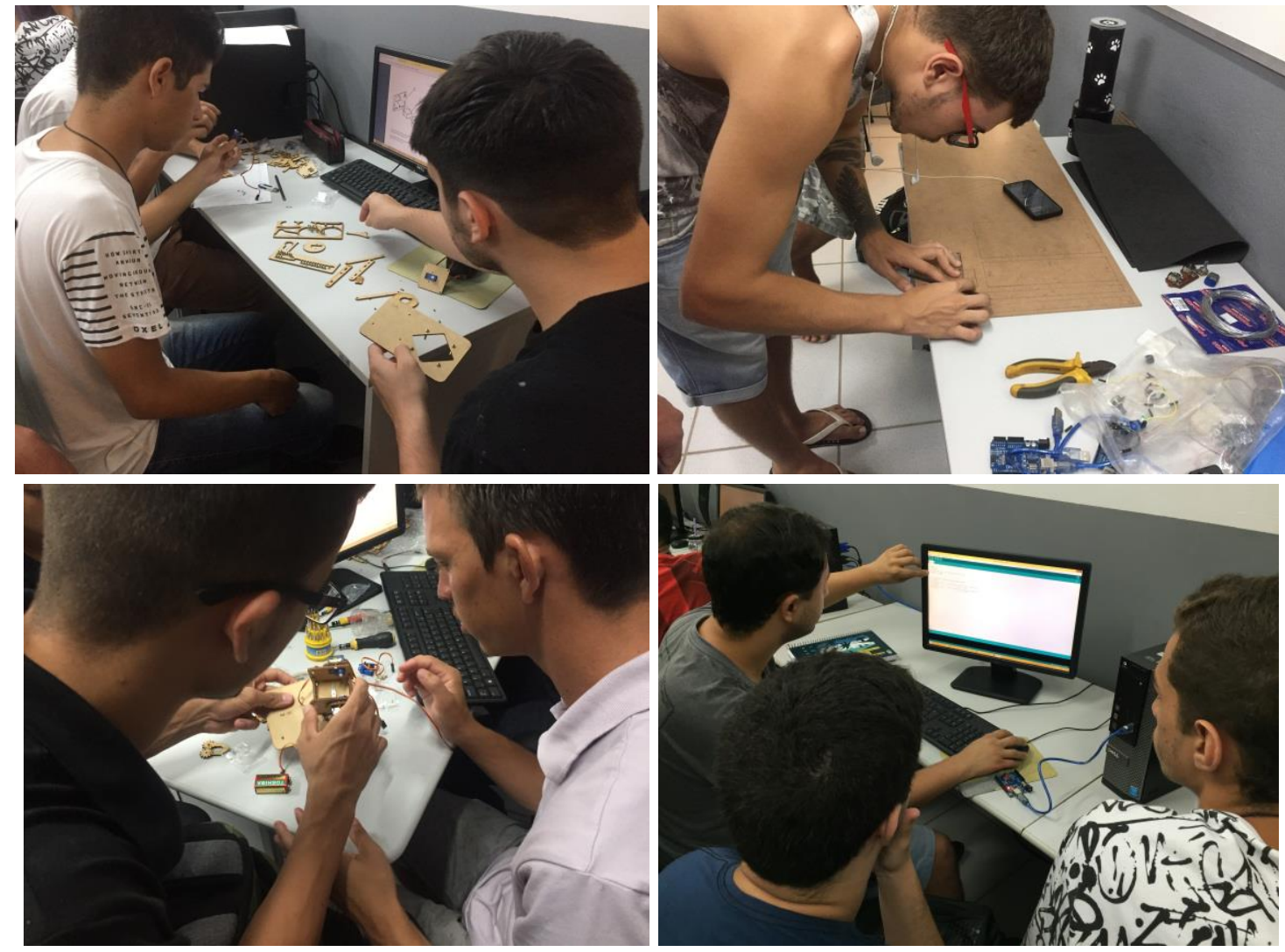

Figura 3 - Alunos trabalhando nas fases de montagem da estrutura de seus projetos robóticos. À esquerda, montagem das partes de um braço robótico de MDF. À direita, acima, riscando partes do projeto, também no MDF e abaixo, discussão e análise de código no Arduino IDE.

Esta fase de manipulação de materiais deu abertura para utilização de outras tecnologias disponibilizadas pela Instituição de Ensino, como Impressora 3D, que imprimiu peças que foram incluídas na estrutura de seus robôs. É significativo ressaltar que a iniciativa de utilização da Impressora 3D como complementação de materiais partiu dos próprios alunos, que elaboraram o projeto 3D, motivados pelo conhecimento adquirido em outra disciplina (de Computação Gráfica).

Esta conexão interdisciplinar motivada pelos próprios discentes também somou positivamente nesta etapa do projeto, principalmente pela capacidade de percepção e possibilidade de utilização de tecnologias ainda não exploradas.

As principais propostas de projetos apresentadas pelos grupos e suas funcionalidades são listadas na Tabela 1, abaixo. Todos os projetos mencionados utilizaram Arduino Uno: 
VIII Congresso Brasileiro de Informática na Educação (CBIE 2019)

Anais do XXV Workshop de Informática na Escola (WIE 2019)

Tabela 1 - Descrição dos Projetos Desenvolvidos.

\begin{tabular}{|l|l|}
\hline \multicolumn{1}{|c|}{ Proposta de Projeto } & \multicolumn{1}{|c|}{ Descrição / Funcionalidade } \\
\hline $\begin{array}{l}\text { Seguidor de Linha } \\
\text { (Figura 4 - Imagem a.) }\end{array}$ & $\begin{array}{l}\text { Robô cuja base é um chassi de carrinho, utiliza sensor } \\
\text { infravermelho para detecção de obstáculos. Neste caso, ele é capaz } \\
\text { de detectar uma linha preta fixada no chão, e segui-la. Motores DC } \\
\text { 3-6V dão movimento ao robô. }\end{array}$ \\
\hline $\begin{array}{l}\text { Guindaste } \\
\text { (Figura 4 - Imagem b.) }\end{array}$ & $\begin{array}{l}\text { O guindaste é capaz de pegar cargas e seu movimento é feito } \\
\text { através de um micro Sevo Motor 9g SG90. Este por sua vez é } \\
\text { controlado por um Potenciômetro que, conforme é girado, reflete } \\
\text { no movimento do guindaste. }\end{array}$ \\
\hline $\begin{array}{l}\text { Elevador de Carga } \\
\text { (Figura 4 - Imagem c.) }\end{array}$ & $\begin{array}{l}\text { O elevador é pré-programado pelo Arduino para realizar } \\
\text { movimento de subida e descida. O movimento dá-se através de um } \\
\text { Motor DC 3-6V. }\end{array}$ \\
\hline $\begin{array}{l}\text { Braços Robóticos } \\
\text { (Figura 4 - Imagem d.) }\end{array}$ & $\begin{array}{l}\text { Foram criados três projetos de braço robótico (um em acrílico e } \\
\text { dois em MDF). Cada um dos braços utiliza para movimento quatro } \\
\text { micro Servo Motores 9g SG90. Dois braços utilizaram controle por } \\
\text { joystick e um controle por interface gráfica e também } \\
\text { potenciômetros. }\end{array}$ \\
\hline $\begin{array}{l}\text { Esteira "Inteligente" } \\
\text { (Figura 4 - Imagem e.) }\end{array}$ & $\begin{array}{l}\text { A mini esteira transportadora utiliza Sensor Ultrassônico que é } \\
\text { capaz de detectar quando um objeto é passado por ela. Fazendo } \\
\text { então a contagem e mostrando no visor LED. }\end{array}$ \\
\hline
\end{tabular}

As aulas práticas se sucederam semanalmente e trouxe consigo muitos desafios, como problemas de hardware e software que foram solucionados colaborativamente entre membros do grupo e até mesmo intergrupos.

Neste ponto do relato, podem-se citar dois exemplos de experiências positivas que foram observadas entre os alunos. O primeiro caso trata-se de uma dificuldade de hardware, no projeto da Esteira Inteligente, onde o Motor DC estava sendo acionado, entretanto não girava sem um impulso manual. Para manipular o Motor DC foi utilizado um Driver Ponte H L298N, que é um módulo de controle de velocidade. Através da monitoração diária (apesar das aulas serem semanais) e depois de significativas tentativas, o grupo obteve êxito no entendimento com a mediação dos demais grupos no que se mostrava como dificuldade de entender a forma do funcionamento do motor. Com esta vivência o grupo teve a possibilidade de ampliar a construção de conhecimentos com um estudo complementar sobre circuitos de uma Ponte $\mathrm{H}$ e sobre PWM (Modulação de Largura de Pulso, que é uma técnica utilizada para gerar sinais analógicos em um dispositivo digital, que era exatamente o que precisava ser feito para resolver a problemática apresentada).

O segundo caso, abordou um problema de software, no projeto do Guindaste. Ao girar o controle para que o motor se movesse em uma direção, o mesmo girava, porém, retornava para a posição inicial logo em seguida. Dentro do programa, o grupo entendeu o que precisava ser trabalhado e modificado, depois de árduas pesquisas. Estes dois relatos foram notáveis devido ao fato de que toda resolução do problema foi encontrada, de forma independente, por alunos iniciantes.

Os projetos finalizados foram apresentados em uma Mostra de Robótica e Inovação que premiou, com certificados de honra, os alunos que apresentaram o melhor projeto. A premiação criou um ambiente de competitividade positiva entre os grupos. 
VIII Congresso Brasileiro de Informática na Educação (CBIE 2019)

Anais do XXV Workshop de Informática na Escola (WIE 2019)

A Figura 4 expõe cinco projetos que foram apresentados na Mostra, todos estavam em perfeito funcionamento e de acordo com a descrição da Tabela 1.

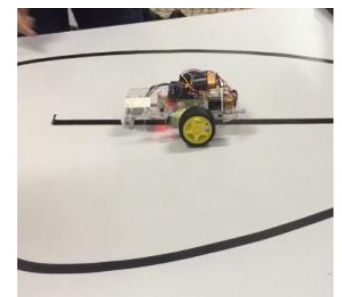

a.

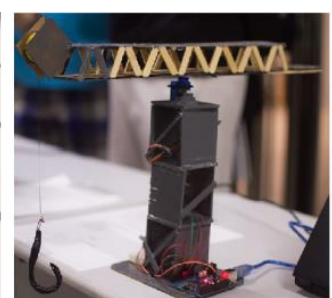

b.

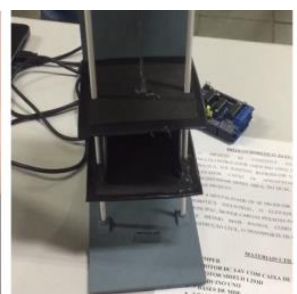

c.

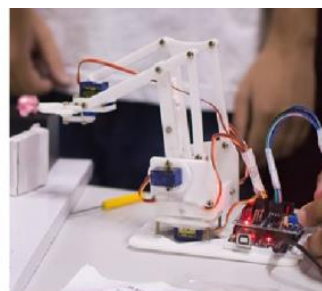

d.

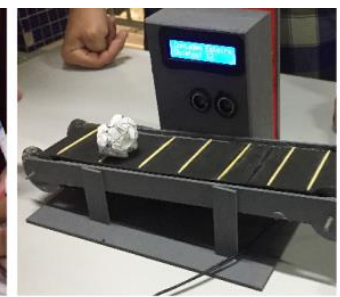

e.

Figura 4 - Projetos Finais apresentados na Mostra de Robótica e Inovação da Instituição de Ensino. Da esquerda para a direita: Seguidor de Linha, Guindaste, Elevador, Braço Robótico e Esteira Transportadora.

\section{A importância do Professor como Mediador da Utilização da Robótica para a Educação}

As experiências na disciplina mostraram que a utilização de instrumentos de robótica não desconsidera a mediação do professor, isto pode ser constatado nos momentos de elaboração e programação da disciplina, combinado com o projeto pedagógico do curso, $\mathrm{e}$, no decorrer as aulas onde ele atua como mediador das aprendizagens.

A presença considerável de tecnologias e dispositivos eletrônicos nas instituições de ensino aponta sobre o impacto do avanço tecnológico no cotidiano (computador, Internet, videogames, redes sociais, smartphones e tablets, smartwatches). Entretanto, os recursos e métodos de ensino dificilmente conseguem se desvencilhar do tradicionalismo que privilegia a replicação de conhecimentos já estabelecidos, como acontece na maioria das instituições de ensino desde as salas de aula tradicionais (com as carteiras dispostas uma atrás da outra em um formato que perdura há anos) até dinâmicas centradas apenas no professor [Victal, 2015].

Pode soar como exagero, mas, se analisado historicamente, muitas das áreas das atividades humanas sofreram progressos, como as telecomunicações, o lazer e os transportes, tal como a Medicina. A Escola, no entanto, até pouco tempo atrás, não havia mudado tanto assim em comparação com as outras áreas [Papert, 1994].

Por outro lado, existe uma expectativa de mudança desse cenário, o que já vem pouco a pouco acontecendo, através de uma demanda por novos recursos pedagógicos. É um grande desafio, mas, como visto na Seção 2, que vale a pena, devido aos bons resultados que pode apresentar. $\mathrm{O}$ aparecimento gradual de tecnologias requer novos comportamentos por parte dos profissionais da educação, pois como dito acima, ele deixa de ser apenas um transmissor de conhecimento e passa a ser um mediador, um facilitador da aquisição desse conhecimento, estimulando a criação e a produção.

É importante também que o professor conduza a robótica como parte integrante dos projetos das disciplinas e não como acessório utilizado apenas cosmeticamente para "dar um ar de modernidade". O uso de tecnologias como a robótica provocam a imersão e, dessa forma, o aluno, aprende até mesmo brincando. Isso traz a possibilidade de reflexão sobre as formas de atuar do professor, que deve estar preparado e aberto para pensar em novas formas de ser um mediador no fazer de suas práticas. 
VIII Congresso Brasileiro de Informática na Educação (CBIE 2019)

Anais do XXV Workshop de Informática na Escola (WIE 2019)

\section{Conclusões}

A produção de conhecimento experienciada pelos grupos de alunos foi muito significativa e esperamos que possa contribuir para os docentes que desejem experimentar o uso a robótica como ferramenta pedagógica em suas salas de aula.

Frisar com clareza e constantemente os objetivos dessa aplicação, que é a potencialização da aprendizagem, é necessário para deixar entendido pelos alunos o conceito de aprendizagem e também quais habilidades e competências serão desenvolvidas. Compreender o conceito de aprendizagem se faz necessário porque no início não se tem uma percepção do que ela é e do principal objetivo do ensino. Com relação às habilidades e competências, possibilita que os docentes tenham o conhecimento dos resultados esperados dos usos digitais, gerando, consequentemente, um maior engajamento.

Quanto ao relato de experiência narrado neste artigo, toda dinâmica dos processos gerais e também em cada etapa, atingiu êxito nos resultados esperados. Analisando o processo como um todo, a Mostra de Robótica e Inovação confirmou a capacidade dos discentes menos experientes para entregar os projetos funcionando de acordo com o proposto inicialmente. Analisando as etapas, elas funcionaram como uma cadeia evolutiva, seguindo fases de planejamento bem sucedidas.

Toda dinâmica aplicada nas aulas mostrou eficiência como facilitadora de apresentação de conteúdo teórico, muitas vezes por assimilação à parte prática. $\mathrm{O}$ fato da entrega dos projetos finais serem por meio de uma Mostra aberta a toda instituição de ensino, com premiação do melhor projeto, também foi uma estratégia adequada, que gerou um comprometimento, dedicação e envolvimento ainda maior.

Este artigo tem por objetivo explicitar esse relato de proveitosas experiências com robótica para outros pesquisadores e docentes como uma forma de cativar e incentivar o uso e inserção de tecnologias digitais em sala de aula e trazer reflexões sobre os processos de ensino aprendizagem e de como pode ser proveitoso trazer novas possibilidades no fazer da educação.

\section{Referências}

Benitti, F. B. V., Vahldick, A., Urban, D. L., Krueger, M. L., Halma, A. (2009) "Experimentação com Robótica Educativa no Ensino Médio: Ambiente, Atividades, Resultados”. In: XV Workshop de Educação em Computação, Bento Gonçalves, RS.

Bortolazza, C., Ribeiro, D. J. e da Silva, W. L. O. (2014) "O Uso da Robótica Educacional em Aulas Práticas de Física no Ensino Médio”. In: Anais do IV Simpósio Nacional de Ensino de Ciência e Tecnologia, pp. 1-9.

Campos, F. (2012) "Design instrucional e construtivismo: em busca de modelos para o desenvolvimento de software". RIBIE.

do Rocio Zilli, S. (2004) "A Robótica Educacional no Ensino Fundamental: Perspectivas e Prática". In: Dissertação de Mestrado contida no Repositório Institucional da Universidade Federal e Santa Catarina (UFSC).

Lopes, A. R., Cruz, E. D. N., Siebra, C. A. (2018) "Uma Análise com Foco Quantitativo sobre o Uso da Robótica Educacional no Ensino da Física". In: Anais do XXIX Simpósio Brasileiro de Informática na Educação (SBIE 2018). 
VIII Congresso Brasileiro de Informática na Educação (CBIE 2019)

Anais do XXV Workshop de Informática na Escola (WIE 2019)

Moretto, V. P. (2000) “Construtivismo: a Produção do Conhecimento em Aula”. 2 V. DP\&A: Rio de Janeiro.

Papert, S. "A Máquina das Crianças: Repensando a Escola na Era da Informática" (1994). Artes Médicas: Porto Alegre.

Piaget, J. "Epistemologia Genética” (1970). Petrópolis: Vozes.

Rapkiewicz, C. E., Falkembach, G., Seixas, L., dos Santos Rosa, N., da Cunha, V. V., Klemann, M. (2006) "Estratégias Pedagógicas no Ensino de Algoritmos e Programação Associadas ao Uso de Jogos Educacionais”. In: Revista Novas Tecnologias na Educação (RENOTE).

Thiollent, M. (1985) “Metodologia para pesquisa-ação”. São Paulo: Cortez.

Victal, E. R. D. N, Pereira Junior, H. A., Rios, P. T. G., Menezes, C. S. (2015) “Aprendendo sobre o uso de Jogos Digitais na Educação". In: XXI Workshop de Informática na Escola (WIE 2015).

Zanetti, Humberto A., Bonacin, Rodrigo (2014) "Uma Metodologia Baseada em Semiótica para Elaboração e Análise de Práticas de Ensino de Programação com Robótica Educacional”. In: Anais do XXV Simpósio Brasileiro de Informática na Educação (SBIE 2014). 